\title{
The case for banning cigarettes
}

\author{
Kalle Grill, ${ }^{1}$ Kristin Voigt ${ }^{2,3}$
}

${ }^{1}$ Department of Historical, Philosophical and Religious Studies, University of Umeå, Umea, Sweden

${ }^{2}$ Ethox Centre, Nuffield Department of Population Health, University of Oxford, UK

${ }^{3}$ Institute for Health and Social Policy \& Department of Philosophy, McGill University, Canada

Correspondence to Dr Kristin Voigt, Ethox Centre, Nuffield Department of Population Health, University of Oxford, Old Road Campus, Oxford OX3 7LF;

kristin.voigt@ethox.ox.ac.uk

Received 18 May 2015 Revised 12 October 2015 Accepted 22 October 2015 Published Online First 17 November 2015

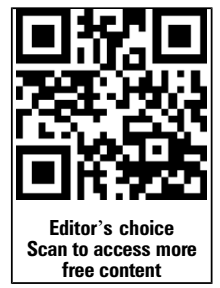

\section{SLinked}

- http://dx.doi.org/10.1136/ medethics-2015-102974

\section{CrossMark}

To cite: Grill K, Voigt K. J Med Ethics 2016;42: 293-301.

\section{ABSTRACT}

Lifelong smokers lose on average a decade of life vis-àvis non-smokers. Globally, tobacco causes about 5-6 million deaths annually. One billion tobacco-related deaths are predicted for the 21st century, with about half occurring before the age of 70 . In this paper, we consider a complete ban on the sale of cigarettes and find that such a ban, if effective, would be justified. As with many policy decisions, the argument for such a ban requires a weighing of the pros and cons and how they impact on different individuals, both current and future. The weightiest factor supporting a ban, we argue, is the often substantial well-being losses many individuals suffer because of smoking. These harms, moreover, disproportionally affect the disadvantaged. The potential gains in well-being and equality, we argue, outweigh the limits a ban places on individuals' freedom, its failure to respect some individuals' autonomous choice and the likelihood that it may, in individual cases, reduce well-being.

\section{INTRODUCTION}

Lifelong smokers lose on average a decade of life vis-à-vis non-smokers. Globally, tobacco causes about 5-6 million deaths annually. ${ }^{1}$ This number is expected to grow: a total of one billion deaths are predicted during the 21 st century, with about half occurring before the age of $70 .{ }^{12}$ It is against this background that we will argue for a complete ban on the sale of cigarettes. While our argument focuses on tobacco cigarettes, which in many countries are by far the most popular tobacco product and in the aggregate the most harmful, we think it could be extended to include other forms of combustible tobacco as well.

As with many policy decisions, the argument for a ban requires a weighing of its pros and cons, including its impact on different individuals, both current and future. The weightiest factor supporting a ban, we argue, is the often substantial wellbeing losses many individuals suffer as a result of smoking. These harms, moreover, disproportionately affect the disadvantaged. The potential gains in well-being and equality, we argue, outweigh the limits a ban places on individuals' freedom, its failure to respect some individuals' autonomous choice and the likelihood that it may, in individual cases, reduce well-being.

The idea of a complete ban on the sale of cigarettes is not new. Bans were in place in 15 US states from 1890 to 1927, and Bhutan has had a ban since $2004 .^{3}$ Bans on the sale of (at least some) tobacco products have also been endorsed by members of the international tobacco control community. ${ }^{3-6}$

In order to bring into focus the fundamental normative issues surrounding a ban on sales, we will simplify our discussion in two ways. First, we assume that a ban would be effective. In the real world, of course, any all-things-considered judgement must be informed by an assessment of a ban's likely effectiveness in different contexts, with due consideration of problems such as smuggled cigarettes and black markets. Second, we focus on a complete ban on sales, comparing this only to the status quo and not to the full range of policy alternatives. ${ }^{i}$ We believe that the necessary debate about different policy instruments in various contexts will be greatly facilitated by consideration of the principled argument for a perfectly effective ban, which is what our paper seeks to provide.

We discuss smoking as a global problem, although most real bans would likely be implemented domestically and our argument might have to be adapted to reflect the situation of individual countries or regions. In rich countries, factors such as the greater availability of cessation resources and information about the risks of smoking make a ban less warranted than in countries where much of the population may be unaware of the risks associated with smoking. We therefore focus our discussion on rich countries in order to tackle the most challenging case for our position. This should not detract from the fact that the majority of death and disease a global ban would prevent will occur in low-income and middle-income countries.

We begin by considering the impact of smoking on health and well-being (section 'Health and wellbeing') and the egalitarian effects of a ban (section 'Equality'), both of which will be central to our argument. We then discuss how individual freedom and autonomy are affected by a ban in the section 'Freedom and autonomy'. The sections 'Voluntariness', 'Irrationality' and 'Preferences and endorsement' consider three putative aspects of smoking choices that have been emphasised in the literature: non-voluntariness, irrationality and inconsistency with smokers' endorsed preferences. These aspects do strengthen the argument for a ban, but their role is different from what is often proposed. In 'Banning cigarettes: pros and cons', we bring together these various considerations and explain why overall they speak in favour of a ban. The final section concludes by briefly commenting on how e-cigarettes could help address some of the problems and opposition facing a ban on conventional cigarettes.

\footnotetext{
${ }^{\mathrm{i}}$ Note that many proposals are not alternatives to a ban but rather strategies for its implementation. This includes gradual phase-out schemes, such as the Tobacco Free Generation legislation currently under consideration by Tasmania's government. ${ }^{7}$
} 


\section{HEALTH AND WELL-BEING}

The health risk of smoking naturally varies with the extent of tobacco use. Long-time smokers face significantly increased health risks, including higher risks of lung and other cancers, cardiovascular disease and chronic obstructive pulmonary disease. Significant differences in mortality rates between smokers and never-smokers become apparent from middle age onwards. ${ }^{8}$ Studies suggest a 10-year to 11-year difference between the lifespans of long-term and never-smokers. ${ }^{8}{ }^{9}$ In addition, smoking is implicated in causing many non-fatal conditions that can substantially lower individuals' quality of life, ranging from asthma, tuberculosis, digestive problems and gum disease to vision problems, reduced fertility as well as impotence. $^{10}$

While heavy tobacco use is of course more harmful than light use, even light use, when long term, yields substantial health risks, in some respects approximating those of long-term heavy use. For example, ischaemic heart disease risk is similar in light, intermittent and heavy smokers. ${ }^{11}$ With respect to lung cancer, for men smoking 1-4 cigarettes per day, the risk is three times that of never-smokers; for women, it is five times as high. ${ }^{12}$

Conversely, cessation-which an effective ban would ensure -is associated with substantial health benefits. While for those who quit before their 30 s excess mortality is reduced almost to the level of never-smokers, even those who quit at the ages of 40,50 and 60 gain about 9, 6 and 3 years of life expectancy, respectively. 89

We believe that a comprehensive argument for a ban should look beyond health to overall well-being: improving health outcomes would not be worthwhile if this left people worse off overall. Many health risks are quite reasonably considered worth taking by the individuals concerned because of the benefits they bring in other, non-health areas of their lives.

While there may be disagreement in specific instances, on most accounts of well-being both the premature mortality and various diseases associated with smoking will reduce lifetime well-being. On hedonist views, the pain and frustration associated with non-fatal diseases typically decrease well-being with no countervailing benefit. Regarding mortality, life is, with some tragic exceptions, on balance a positive experience, and so more life is better. On preferentist or desire-based views, more of a person's most important preferences will typically be satisfied, and fewer frustrated, if she lives longer and has better health. A longer and healthier life also advances typical objective list entries such as developing and sustaining human relationships, and various moral and rational pursuits. Even if one refrains from specifying the nature of well-being, in line with liberal neutrality, long life and good health are all-purpose means that contribute to the pursuit of almost any life plan.

Importantly, we do not deny that smoking can also promote well-being in certain respects; in fact, we will emphasise below that it can do so and consider the possibility that there may be individuals for whom smoking leads to an overall gain in wellbeing. However, in the aggregate, the negative well-being effects of smoking are likely much larger than its positive effects.

\section{EQUALITY}

Smoking also contributes to inequality. Most obviously, smokers are, to varying degrees, worse off than non-smokers because of the health risks and the monetary costs associated with smoking. Less obviously, because of the denormalisation of smoking, smokers are increasingly stigmatised and discriminated against. ${ }^{13} 14$
What makes smoking particularly problematic from the point of view of equality is that it disproportionately harms people who are disadvantaged in other regards. In many rich countries, smoking rates are significantly higher among low-income groups. In the UK, for example, smoking prevalence in routine or manual occupations is $30 \%$ while in managerial and professional occupations it is $16 \% .^{15}$ Among the most deprived groups, smoking rates reach $>70 \%$; among homeless people sleeping rough, $90 \%$ are smokers. ${ }^{16}$

Of course, not all disadvantaged people smoke, and not all smokers are disadvantaged, socio-economically or otherwise. In the aggregate, however, a ban could help reduce inequalities in health outcomes. Studies suggest that, in Europe, smoking could be the largest single contributor to socio-economic inequalities in health, particularly among men. ${ }^{17}$ In the UK, tobacco is considered the cause of about half of the socioeconomic status difference in death rates. ${ }^{18}$

Many factors may contribute to unequal smoking rates. Smoking norms vary substantially across different groups. ${ }^{19}$ In deprived communities, smoking often plays an important social role. ${ }^{20}$ Support with cessation, including nicotine replacement therapy (NRT), counselling and medical advice, may also be more accessible for those from better-off groups. Further, the tobacco industry has specifically targeted disadvantaged populations, for example by placing its advertising disproportionately in low-income and ethnic minority neighbourhoods ${ }^{21} 22$ and devising marketing strategies with particular appeal to the homeless and those with mental health problems. ${ }^{23}$ These factors may help explain differences in cessation rates: studies suggest that across social groups smokers make similar numbers of cessation attempts but those in better-off groups are more likely to succeed. ${ }^{24}$ It is an ongoing concern that many tobacco control strategies have greater effects on cessation rates among better-off groups vis-à-vis disadvantaged groups; ${ }^{25}$ ii an effective ban would enforce cessation equally across social groups, avoiding these inegalitarian effects.

The idea that a ban would enhance equality in health outcomes assumes that those who quit as a result of a ban will substitute smoking with something less harmful to their health. The fact that, as we noted above, cessation is associated with such substantially improved health outcomes suggests that those who quit do so in ways that are overall beneficial for their health. It is not implausible that many of those who would quit as a result of a ban (many of whom, as we note below, are very motivated to quit) would see similarly improved health prospect. However, much will depend on how exactly a ban is phased in and the extent to which it is accompanied by measures to help smokers quit.

Our assessment of a ban should be based on its likely effects not only on health inequalities but on inequalities more broadly conceived. One important concern is that, while unequal smoking rates across different socio-economic groups mean that the health loss averted by a ban should be much greater among disadvantaged groups, a ban could also impose additional burdens on these smokers. As Gostin emphasises, a complete ban would leave many highly addicted smokers in withdrawal and distress, ${ }^{26}$ many of them from vulnerable populations, including the poor, prisoners and the homeless, as well as those with mental health problems, for whom the immediate effects

ii A possible exception to this appears to be increased taxation. However, taxation comes with a set of egalitarian concerns of its own; see Voigt ${ }^{19}$ for further discussion. 
of quitting might be more complicated and/or more difficult to deal with. ${ }^{27}$

More generally, being disadvantaged-be it socioeconomically or in other ways-may also affect people's ability to respond or adapt to a ban. Different ways of 'phasing in' a ban might help address these concerns, as could the availability of suitable substitutes, such as e-cigarettes. For example, a ban could be accompanied by free NRT for those on low incomes, prison populations or those in mental health institutions.

For some smokers, the burdens imposed by a ban may be so significant that they will not be compensated for by the benefits cessation would bring; smokers in their 80 s or 90 s might be a case in point. Limited licensing schemes might be a suitable strategy for this group. Importantly, as we explain in more detail below, these concerns arise in relation to the current generation of smokers and will have much less significance with respect to future generations, who-because of the ban-would not become smokers in the first place. We return to this issue in the section 'Banning cigarettes: pros and cons'.

\section{FREEDOM AND AUTONOMY}

An important concern about our proposal is that a ban would pose an undue restriction on individual freedom and autonomy. Regarding freedom, we accept that any restriction of the available opportunities reduces freedom of choice. ${ }^{\text {iii }}$ However, more freedom is not always better, nor is it always preferred. The disvalue of a particular restriction on freedom depends both on the interest people have in using the opportunity that is being removed, and on the interest people have in having or keeping the opportunity as an opportunity, whether or not they use it. Even non-smokers may have an interest in having the opportunity to smoke: this might be quite a specific interest (eg, in resisting temptation) or a more general interest in having a wide range of options.

Autonomy we understand here as self-direction, involving both an internal and an external aspect. Internal autonomy is the absence of internal obstacles to self-rule, such as ignorance, poor self-confidence or sense of self-worth, incoherent desires or preferences, and various psychological conditions such as clinical depression and obsessive-compulsive disorder. External autonomy is the absence of external obstacles to selfrule, most obviously various malign influences from others to manipulate one's deliberations and so undermine one's independence. ${ }^{\text {iv }}$ So understood, a ban will not necessarily reduce autonomy. Quite to the contrary, to the extent that a ban frees many smokers of a debilitating addiction, it strengthens their internal autonomy.

A ban may fail to respect individual autonomy. Respecting autonomy, we propose, requires abstaining from frustrating the choices of relatively autonomous people. We accept that there are strong reasons to respect autonomy in this sense. While significant shortfalls from full autonomy reduce our reasons to respect choices, they do not fully eliminate such reasons; interference still requires some justification. ${ }^{\mathrm{v}}$ Indeed, since people are typically quite prone to make choices that are far from fully

\footnotetext{
iii This is in accordance with the mainstream liberal tradition whose proponents include Isaiah Berlin, ${ }^{28}$ Joel Feinberg ${ }^{29}$ and Ian Carter. ${ }^{30}$ This is, we believe, a quite intuitive way to think about freedom.

${ }^{\text {iv }}$ By defining autonomy negatively, we hope to remain somewhat neutral between various more substantial accounts. Sometimes, external autonomy is taken to require freedom (ref. 31, p. 204). Since we consider freedom separately, we will leave this possibility to the side here.
}

autonomous, we think that almost any choice should warrant some respect. Note that one may choose something even if one does not find the freedom to do so important, or indeed even if one would prefer not to have this freedom. Such choices indicate some sort of inner conflict, but it may still be disrespectful of others to interfere with them.

Freedom and respect for autonomy, as we have described them, can pull in different directions when it comes to evaluating a ban on cigarettes. An autonomous smoker may choose to restrict her own freedom to smoke. For example, she may engage her partner in keeping their shared home free of cigarettes. If someone prevents her from making this arrangement, this protects her freedom to smoke but fails to respect her autonomy. Similarly, smokers may try to engage their government in keeping their society free of cigarettes (in fact, many smokers would welcome a ban imposed by the government; we return to this issue in the section 'Preferences and endorsement'); for these smokers, a ban, by restricting their freedom, will respect their autonomy.

Respect for autonomy can also part ways with well-being considerations. A person may autonomously choose to smoke because she does not care about her future well-being or because she falsely believes that a shorter and less healthy life will not decrease her well-being (eg, because she believes, at 21, that she will never want to live past the age of 40 anyway). We have reason both to respect this choice and to protect this person's lifetime well-being.

The next three sections address three related considerations that have been taken to strengthen the case for a ban: the degree to which smoking choices are less than fully voluntary, the limited rationality of these choices and the fact that many smokers do not endorse their smoking choices. Sometimes, these factors are explicitly invoked in relation to freedom or autonomy, sometimes they are invoked as arguments in their own right. As will become apparent, we believe that these considerations can indeed play an important role in the argument for a ban; however, their role has been overstated in the literature and must be qualified in various respects.

\section{VOLUNTARINESS}

The most comprehensive philosophical argument for strict regulation of smoking (though not explicitly a complete ban on cigarettes) has arguably been put forth by Robert Goodin, especially in his 1989 book, No Smoking: The Ethical Issues. One of Goodin's central arguments for tobacco regulation starts from the idea that because smokers typically have not fully appreciated the risks of smoking, and because smoking is addictive, the associated risks are not voluntarily assumed. This, in Goodin's argument, makes interference with smoking choices much less problematic than interference with other kinds of choices.

Goodin proposes that people are often not sufficiently informed about the consequences of smoking. Being sufficiently informed, on his account, requires not only being able to state the relevant probabilities about risks but also to 'appreciate them in an emotionally genuine manner' (ref. 33, p. 24, citing Gerald Dworkin ${ }^{34}$ ). Goodin does not seem to believe that being uninformed completely removes any reasons against regulation, but rather that the less informed a choice is, the less reason we have to abstain from frustrating it (ref. 33, p. 21).

${ }^{v}$ For an extensive treatment of respect for less than fully autonomous choice, see Grill. ${ }^{32}$ 
We share Goodin's concern that smokers must know the risks associated with smoking if we are to fully respect their choice to smoke. Knowledge of the risks of smoking is now well spread in developed countries, but much less so in many developing countries, ${ }^{35}$ making the concern about involuntarily incurred risk highly relevant in these countries. This is important not least because $82 \%$ of the world's smokers currently live in lowincome and middle-income countries. ${ }^{36}$

However, Goodin's claim that in order to be sufficiently informed we must also have an emotionally genuine appreciation of these risks amounts to a very strong requirement. It may be very difficult for a 20 -year-old to appreciate, 'in an emotionally genuine manner', the suffering she might endure as a victim of emphysema 40 years later, especially if she lacks experience of major illness in herself or those close to her. Such a demanding requirement may be more reasonable for choices with immediate effects, but one of the problems with smoking is precisely that people typically start young and suffer the consequences much later. Goodin's criterion of what counts as informed choice may turn out to be too high a bar to clear for most of the choices people make, including our most important choices, such as whether and with whom to have children. On Goodin's account, we have strong reasons to interfere with such choices if we believe them to be unwise. It is beyond the scope of this article to fully engage with Goodin's arguments on its own terms. However, we believe that the best argument for a tobacco ban does not depend on such a controversial interpretation of informed choice. We think that the argument for a ban can succeed even if we accept that we have strong reasons to respect the choices smokers make, even if they do not fully appreciate the risks of smoking.

The second factor Goodin emphasises is the addictiveness of smoking. He argues that while it is not impossible to overcome addictions, what matters normatively is whether the addictiveness makes it 'unreasonably costly' (ref. 33, p. 25) to do so: if the addiction is so strong "that even someone with 'normal and reasonable self-control' would succumb to it, we have little compunction in saying that the addict's free will was sufficiently impaired that his apparent consent counts for naught" (ref. 33, pp. 25-6, citing Gary Watson ${ }^{37}$ ). This condition, Goodin argues, is met in the case of smoking. Thus, a smoker's continuing to smoke cannot be taken as consent to the risks involved. Further, many smokers become addicted below the age of consent and so, Goodin argues, they cannot be taken to have consented to the risk of becoming addicted to nicotine.

While we share some of Goodin's concerns about the implications of addiction, the heterogeneity of smokers means that his argument applies to fewer smokers than Goodin suggests. Consider first the matter of age. It is often claimed that the quota of smokers who become addicted below the age of 21 is extremely high; Goodin puts this number at 95\%. However, these numbers are typically based on studies that ask respondents at what age they first started smoking. This question may lead them to focus on their first ever cigarette, which need not indicate the beginning of addiction. Studies that instead ask respondents when they started smoking regularly indicate that the number of smokers who took up smoking as minors is substantially smaller. Surveys of UK smokers indicate that 55-66\% start before the age of 18 (ref. 38, p. 42, ref. 39, p. 11).

Even regular smoking, however, is not necessarily a good indicator of addiction. Some adolescents may be able to maintain intermittent smoking without developing dependence. ${ }^{40}$ Among adults, too, not all smokers become dependent. One study finds that almost $40 \%$ of daily smokers fail to meet the criteria of nicotine dependence (though they may exhibit individual symptoms of addiction, such as difficulties abstaining from cigarettes). ${ }^{41}$ While there is disagreement about how to define addiction and what proportion of smokers meet the required criteria, there may be a significant proportion of smokers to whom this part of Goodin's argument does not apply.

Furthermore, it is not clear that addiction fully undermines the voluntariness of smoking in all regards. Even if addiction makes it 'unreasonably costly' to abstain from one's next cigarette, there may still be scope for devising a longer-term cessation strategy. This kind of long-term planning is arguably less susceptible to the forces of addiction. The addictiveness of tobacco may of course still thwart any cessation attempts smokers do make (we return to this below); but Goodin's argument, by not addressing this issue, proceeds too quickly.

Finally, irrespective of the degree to which addictiveness undermines the voluntariness of smoking, we are more concerned than Goodin that we have some reason to abstain from frustrating even those choices that are substantially nonvoluntary. As John Christman notes, "I might know that a person is to some degree under the sway of external pressures that are severely limiting her ability to govern her life and make independent choices. But as long as she has not lost the basic ability to reflectively consider her options and make choices, if I intervene against her will (for her own good), I show less respect for her as a person than if I allow her to make her own mistakes". 42

Our scepticism about Goodin's argument should not be taken to imply that we think addictiveness is irrelevant. It is certainly true that many smokers are addicted and have become addicted in their youth; we agree that we have less reason to respect these smokers' choice to smoke. Moreover, the addictiveness of smoking is often an intermediary cause in people becoming long-term smokers and thus facing substantial health risks. However, the lack of consent argument may apply to a smaller proportion of smokers than Goodin suggests.

More generally, we think that the broader concern herewhether or not smokers voluntarily accept the risks of smoking - should play a somewhat different role in the argument. On the one hand, as we have said, the degree of voluntariness affects the degree to which the choices involved are autonomous and so to what degree we have reason to respect them. At the same time, though, even if risks were accepted in a fully voluntary manner, this does not mean that the resulting harm is not undesirable or that we should not seek to prevent it.

Harms can be undesirable even if they result from risks that are voluntarily assumed. If, for example, I risk my health by donating a kidney to a relative, this does not detract from the undesirability of any ensuing harms. There may be an exception for harms that are actively sought out: a person may want to die, or want to amputate an arm, where this is not merely instrumental to some aim that can be reached in less harmful ways. However, when a person simply accepts a risk of what is for her an undesirable outcome, this is clearly not by itself a reason to disregard the risk or outcome.

Jason Hanna makes a persuasive argument against tying the justifiability of paternalism to voluntarily assumed risks. ${ }^{43}$ Hanna gives the example of a reckless hiker who voluntarily abstains from gathering information on which bridges in the area are dangerous. Later on, the hiker unknowingly starts to cross a dangerous bridge, not because he wants to court danger but simply to finish his hike. If respect for autonomy precludes from moral consideration voluntarily assumed risks, then a 
bystander has no reason to intervene, which seems an unacceptable conclusion (ref. 43, pp. 424-5). Similarly, we cannot conclude that we should abstain from intervening with smoking simply because smokers have voluntarily assumed the health risks.

\section{IRRATIONALITY}

A further concern in the normative debate about smoking and about how governments ought to respond to it is that smoking choices are in some sense irrational. This is the argument Sarah Conly pursues in her recent book, Against Autonomy: Justifying Coercive Paternalism, where she argues that we should often disregard, at least to some extent, smokers' apparent preference for smoking. Goodin takes similar considerations to bolster his argument from lack of consent. The argument from irrationality can start from either impairments in the decision-making of smokers (in particular, cognitive biases) or, relatedly, from a discrepancy between smokers' own goals and their choices.

Invoking impairment, Goodin argues that intervention into the choice to smoke is especially warranted if smokers' false beliefs are caused by cognitive biases. Goodin points to evidence that smokers are subject to three biases, which are now most often called optimistic bias ('wishful thinking'), the availability heuristic ('anchoring') and hyperbolic or temporal discounting ('time discounting'). ${ }^{33}$ As is more thoroughly researched and more widely appreciated now than when Goodin wrote his book, these biases are quite general, and not particular to smokers. ${ }^{44}$ Therefore, either of two conclusions are possible: either the charge that smoking choices in particular are impaired loses its force or the charge is expanded to very many decisions we make. The latter option is the one pursued by Conly.

Conly cites a wide range of research in behavioural psychology and concludes: "We generally suffer from many flaws in instrumental reasoning that interfere with our ability to make effective and efficient choices" (ref. 45, p. 23). The same conclusion has motivated Richard Thaler and Cass Sunstein to promote what they call libertarian paternalism-benevolent structuring of choice situations that does not significantly affect the outcomes of the various options in the choice set. ${ }^{46} 47$ Conly argues that libertarian paternalist measures are insufficient to ensure that people's choices promote their well-being and that we have no good reason to abstain from coercive measures. Her argument, however, is thoroughly consequentialist and does not give a role to respect for autonomy as we understand it. Instead, she assumes that we have reason to respect autonomy only if this is an effective means of promoting some other goal: "the basic premise of liberalism [...] is that we are basically rational, prudent creatures who may thus, and should thus, direct themselves autonomously" (ref. 45, p. 30). Conly rejects this premise and draws the conclusion that "when it comes to respect for autonomy, we can see that our belief that autonomous actions should not be interfered with was based on a mistake" (ref. 45, p. 192).

Since we believe that there is reason to respect an agent's choices, even when these choices do not promote the agent's well-being, we find the argument from irrationality unpersuasive. Behavioural research may have proven that poor instrumental rationality is a general aspect of human decision-making. This, however, does not necessarily undermine our reasons to respect choices that are about as autonomous as choices typically are. What would be more relevant is if smokers in particular were prone to irrationality. There is some evidence that addiction causes behaviour that may be deemed irrational, though this is disputed. ${ }^{\mathrm{vi}}$
We now turn from the proposal that poor instrumental rationality is an impairment to the more consequentialist observation that poor instrumental rationality, impaired or not, is prone to create a discrepancy between goals and actions. It is clear that people make choices that do not further their own well-being. What has been open to interpretation and debate is whether this means that people fail to effectively promote their goals or whether, instead, they might have goals other than furthering their own well-being. The extensive study of cognitive biases has given us some reason to favour the first interpretation: if people are under the constant influence of cognitive bias, we can expect that they will not effectively further their own goals. Therefore, the fact that they do not promote their own wellbeing need not indicate that this is not their goal.

Conly argues that "[w]hat we need to do is to help one another avoid mistakes so that we may all end up where we want to be" (ref. 45, p. 2, emphasis added). Where we want to be, Conly assumes, there are no cigarettes. She describes smoking as a "bad course[] of action" (ref. 45, p. 8) and an instance of people "choos[ing] poorly" (ref. 45, p. 9). Smokers, she says, "spend a disproportionate amount of their income on a habit that will probably leave them in worse health and possibly shorten their life without bestowing compensating benefits" (ref. 45 , p. 33, emphasis added). Goodin similarly argues that "what is involved here is a weak form of paternalism, working within the individual's own theory of the good and merely imposing upon him better means of achieving his own ends" (ref. 50, p. 23, emphasis added).

While we agree that we should be concerned about a possible discrepancy between smokers' goals and their choices, Conly's argument does not give sufficient weight to the fact that many people find smoking pleasurable and enjoy the taste or the buzz and relaxing effects that come from nicotine. As summarised in a recent study, "nicotine induces pleasure and reduces stress and anxiety. Smokers use it to modulate levels of arousal and to control mood. Smoking improves concentration, reaction time, and performance of certain tasks" (ref. 51, p. 2298). The behavioural components of smoking may also be experienced as relaxing. ${ }^{52}$ It is certainly not obvious that the net effect of smoking on well-being is necessarily negative. While Conly briefly discusses pleasure in the context of tobacco and acknowledges the pleasure addicted smokers experience from cigarettes (mainly the pleasure of alleviating withdrawal symptoms) (ref. 45, pp. 170-1), she dismisses too quickly the possibility that those who smoke but are not addicted can derive substantial pleasure from cigarettes. ${ }^{\text {vi }}$ This is particularly important because, as we noted above, a significant portion of smokers may not in fact be addicted.

Could these pleasures indeed outweigh the risks and so make smoking consistent with the goal of furthering one's own wellbeing? This, we think, can vary, depending primarily on an individual's level of tobacco consumption. Consider lung cancer, which is one of the most severe conditions associated with smoking (though, of course, not the only one; lung cancer causes less than half of the excess mortality among smokers). ${ }^{8}$ For heavy, life-long smokers, studies estimate the risk of developing lung cancer over the course of one's life to be up to $25 \%$

\footnotetext{
${ }^{\text {vi }}$ For a range of perspectives, see Elster and Skog; ${ }^{48}$ for a convincing case that addicts do display some particular irrationality, see Rachlin. ${ }^{49}$

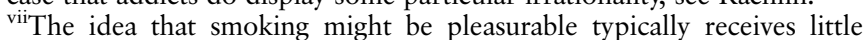
attention in the literature. For an interesting discussion of how the relationship between harm and pleasure is viewed in public health discourses about smoking, particularly in the context of e-cigarettes, see Bell and Keane. ${ }^{53}$
} 
compared with $0.2-1 \%$ for never-smokers. ${ }^{54}$ For these smokers, it seems plausible to claim that the benefits could not possibly outweigh the risks. However, this is much less clear at lower levels of consumption. Though smoking 1-4 cigarettes a day, as noted above, increases the risk of lung cancer by 3-5 times, ${ }^{12}$ this must be seen in relation to the very low risk for neversmokers. Further, while the literature emphasises that there is no 'safe' or 'risk-free' level of tobacco consumption, those who quit before age 30 appear to avoid almost all of the excess mortality risk associated with continued smoking. ${ }^{8} 955$ Given that smoking can further such goals as pleasure, manifesting a romantic nonchalance and social belonging, these risks seem potentially quite acceptable. ${ }^{\text {viii }}$ Moreover, given that the cost of cessation is typically higher than the cost of not starting, it may be more rational to keep smoking than to start.

Further, even when the harms of long-time smoking and the limited benefits it brings combine to make smoking apparently irrational for the typical smoker, it does not follow that we should completely disregard these choices. Some limited irrationality is common and should not automatically undermine respect for individuals' choices. At the same time, outright irrationality, caused by smoking-specific cognitive failures or simply inferred from severe lack of goal orientation, may remove or significantly weaken our reasons to respect choice. To the extent that smokers display such irrationality, this strengthens the case for a ban. However, the degree to which this concern applies to individual smokers will vary and we should be cautious in giving it too much weight in our argument.

While the irrationality of smoking has played an important role in arguments for tight tobacco control, we have emphasised two broad concerns in this section: first, smoking choices may be more rational than is often assumed and, second, even irrational choices warrant more respect than is typically allowed in the literature on smoking. Our argument for a ban on cigarettes focuses instead on the well-being losses it would avert; that people may be irrational and not secure these benefits for themselves in the absence of a ban is an additional consideration in its favour but should play a much smaller role in the argument than it does for Goodin and Conly.

\section{PREFERENCES AND ENDORSEMENT}

A further factor supporting the case for a ban is that smokers often do not endorse their preference for smoking: They have a preference to smoke but also a preference about that preference: they would prefer not to have it. In a 1991 article, Goodin argues that public policy "can hardly be said to be paternalistic in any morally offensive respect [if] the preferences which it overrides are ones which people themselves wish they did not have" (ref. 56, p. 48). For Goodin, the fact that smokers typically go through many failed cessation attempts shows that their preference for smoking is often not endorsed. The preference for quitting, on the other hand, typically has second-order endorsement (ref. 56, pp. 47-48).

\footnotetext{
viii This should not detract from the concern that unfair inequalities can affect the costs and benefits associated with smoking and thereby the extent to which the risks of smoking become acceptable. For example, as we mentioned in the section 'Equality', social norms around smoking vary across social groups, with smoking often playing an important social role in disadvantaged communities but much less so in affluent ones; this means that not smoking can come with a cost for those in disadvantaged communities that does not exist for those in wealthier ones. That this can make the risks of smoking more acceptable in some social groups than others should be viewed as an unfair disadvantage. ${ }^{19}$
}

Studies indeed suggest that the majority of smokers want to quit. US data puts this proportion at $70 \%,{ }^{57}$ UK data at $64 \%$ of smokers. ${ }^{39}$ Further, in a study with participants from Canada, the USA, the UK and Australia, about $90 \%$ of smokers agreed with the statement, "If you had to do it over again, you would not have started smoking". 58 This indicates that many smokers themselves do not find smoking consistent with their goals, lending support both to concerns about irrationality and nonvoluntariness, which we discussed above. It also indicates, more directly, that many smokers are unhappy with their smoking.

However, if (endorsed) preferences are to guide policy decisions, then a policy designed to prevent smokers from smoking may also need to be evaluated based on smokers' preferences about that policy: it is quite possible that I would prefer not to prefer to smoke, but that I also prefer that the government not prevent my smoking. In fact, Goodin seems to assume that smokers will themselves be opposed to regulation (ref. 56, p. 42). It is not clear why, on his account, such preferences about policy would not tell against a ban.

Looking at preferences about a ban, a somewhat different picture emerges. Many smokers would welcome a ban, though not a majority. Studies from the USA, England, Hong Kong, New Zealand and the Australian state of Victoria suggest that among current smokers about 25-38\% would support the introduction of a ban over the next 10 years or so. ${ }^{59-63}$

Where does this leave the argument for a ban? Though Goodin's treatment is not sufficiently sensitive to vast individual variations, the high degree to which smokers want and try to quit certainly weakens those reasons against a ban that are based on respect for autonomy and the value of freedom: it is arguably more important to respect choices that are endorsed by the chooser, and people generally have a greater interest in preserving options that they would like to make use of. We must also consider smokers' preferences about the ban. As noted, studies from several countries indicate that about a third of them support such a proposal; for these smokers, respect for autonomy actually tells in favour of a ban.

Importantly, people will not have equal 'stakes' in this decision. On the one hand, those supporting the ban may be heavy smokers who find themselves unable to quit, seeking to free themselves of a substantial burden on their health, well-being and finances. On the other hand, those who are not addicted and enjoy the occasional cigarette may find that a ban removes a source of pleasure for them. Non-smokers, too, may value the opportunity to smoke; as we noted above, people can value opportunities even if they have no intention of making use of them. However, if-as seems likely-very few non-smokers actually have any intention of using this option, their interest in keeping it open should weigh much less heavily in decisions about tobacco control. Simply 'adding up' these different preferences may, therefore, not be an appropriate way to give them the respect they are due. ${ }^{\text {ix }}$

\section{BANNING CIGARETTES: PROS AND CONS}

It is time to bring together the various strands of our argument and consider how they inform the desirability or otherwise of a ban on the sale of cigarettes. Much of the literature on strict tobacco regulation focuses on various ways in which smoking choices are significantly less than fully autonomous-involuntariness, irrationality and lack of endorsement of smoking

${ }^{\mathrm{ix}}$ On respect for divergent preferences in groups, cf. discussion on group consent by Grill. ${ }^{64}$ 
choices are the most prominent considerations in the literature, as we discussed in the preceding sections. We agree that these factors are crucial; however, contrary to how they are viewed by other proponents of strict tobacco regulation (such as Conly and Goodin), these factors do not by themselves establish that a cigarette ban is justified, for two reasons: first, many smokers and/or smoking choices do not in fact meet the identified criterion: a significant proportion of smokers may not be addicted, not all smoking choices reflect an irrational assessment of benefits and risks, and so on. Second, when smoking choices do fall short of requirements of autonomy in these ways, interference with these choices becomes more acceptable but it does not become wholly unproblematic. As we discussed above, the primary concern for us is the well-being loss that is associated with cigarettes. We accept that a ban would interfere with some (reasonably) autonomous choices as well as restrict individual freedom, but these negative implications are far outweighed by the well-being gains a ban would imply for both current and future generations.

What speaks against a ban is, first, its negative effects on freedom, in terms of the loss of a valued opportunity to smoke and, second, its failure to respect the autonomy of the many smokers who apparently choose to smoke. With respect to the first concern, we noted that non-smokers have an interest in keeping the option of smoking open and a cigarette ban will involve a restriction of their freedom, even if they have no intention of consuming cigarettes. While it is important to acknowledge this point, we must also emphasise that this is a fairly minimal cost, especially relative to what is at stake for smokers.

The degree to which smokers value the freedom to smoke is likely to vary. Indeed, about a third would favour a ban, which indicates that they do not value the opportunity to smoke very highly, or at least that this value is outweighed by other considerations. Furthermore, it seems that the majority of smokers plan to quit and wish they had never started. Therefore, the freedom to smoke may be unimportant for many-possibly the majority of-smokers.

Regarding autonomy, we noted that by removing a source of addiction a ban would contribute to many current smokers' internal autonomy. This is, of course, a strong reason in favour of a ban. At the same time, a ban fails to respect the choices of the many people who currently smoke, especially those who wish to continue. We have discussed how lack of voluntariness, irrationality and lack of endorsement may mean that many smoking choices warrant less respect than choices typically warrant. Of these facts, lack of voluntariness due to early smoking initiation and due to addiction, lack of second-order endorsement of the preference to smoke and a positive preference for a ban strike us as the most significant. However, many choices to smoke are not burdened by any of these factors, and even when they are, they warrant some respect.

These concerns with freedom and autonomy must be weighed against what we considered the two main considerations supporting a ban: first, the well-being gained by averting substantial health losses that many individuals would otherwise face. This includes averting the expected increase from the current 5-6 million annual premature deaths from tobacco, many of which occur in middle age, and eventually reducing this number to zero, as well as avoiding many non-fatal but severe health conditions. Second, the positive effects on equality achieved by removing a source of poor health that disproportionately affects those who are already disadvantaged.
We recognised that some smokers' well-being might be negatively affected by a ban. This is most likely for two kinds of smokers. First, those who enjoy smoking and only smoke occasionally and thus face much smaller health risks that are outweighed by the pleasures they gain-think, for example, of people who like to smoke a cigar a few times a year. Second, those who, despite substantial cigarette use, will not see substantial benefits from cessation, for example, because they are very old or fatally ill. Cessation support and limited licensing schemes may help this latter group but do not necessarily address this concern fully. While these burdens should not be downplayed, it must be noted that a ban would lower well-being for only a small minority of people and only for the current generation.

The group that stands to gain the most from a ban, on the other hand, are lifelong heavy smokers for whom the pleasures of smoking are not worth the risks and who, because of tobacco's addictive properties, find it extremely difficult or even impossible to effectively act on their preference not to smoke. These smokers are often among the most disadvantaged in society in other regards. Significant well-being gains can also be expected for those who smoke less, and even much less-as we noted above, even low levels of tobacco consumption can be associated with significant health risks.

As far as the current generation is concerned, then, four factors speak in favour of a ban: first, very large benefits in aggregate well-being. Second, reduced inequality in well-being because the benefits accrue largely to the disadvantaged. Third, improvements in internal autonomy for those who would prefer not to smoke. Fourth, respect for the autonomy of that proportion of the smoking population who want a ban (the evidence we cited suggests that this is about a third). These considerations stand against three opposing considerations: first, diminished well-being for those smokers whose well-being is improved by smoking (which we consider to be a small number of smokers). Second, a reduction in freedom that, as we argued, should be given less weight where non-smokers are concerned, and which is unimportant to many smokers (at least to those who want a ban and perhaps also to many who do not but who do not want to smoke). Third, a ban will fail to respect the autonomy of current smokers-though some of our reasons for such respect are weakened by lack of voluntariness, irrationality and lack of endorsement. This failure of respect is arguably greatest with regard to that proportion of smokers who do not favour a ban (about two-thirds). To us, despite the weighty considerations opposing a ban, the balance is very much in its favour.

Consider now all those potential future people who have not yet faced the choice of whether or not to smoke. With an effective ban, these people will not be tempted by the presence of cigarettes. They will not encounter social settings where smoking is advantageous. They may simply regard smoking a historical curiosity. While their freedom is restricted by a ban, it seems likely that the lost option will be quite insignificant to most of them. Some future people might have improved their well-being by smoking, some will surely oppose the ban and some will think they would have liked to smoke. For some of them, the choice to smoke may have been rational and/or endorsed. We expect, however, that this group will form a small minority and a significantly smaller section of the population than is the subsection of the present population who smoke and oppose a ban. For future people, therefore, the arguments against a ban are much weaker than for current people. The arguments for a ban, on the other hand, are just as strong: wellbeing and equality will be promoted by preventing the harms of 
smoking, for future people as for current people. With respect to future generations, therefore, the case for a ban seems even more clear-cut than for the current generation.

Some of these future people, it should be noted, are already alive, in the form of children who are too young to have faced the choice of whether or not to smoke. Especially in poor countries, this group is not as large as one would like since children encounter smoking very early. Still, $>600$ million people are below the age of five. ${ }^{\mathrm{x}}$ This group will supply many of the 10 million annually who are expected to face premature death from smoking from 2050 and on. For them, as well as for future people, the case for a ban seems overwhelming.

For those who consider freedom and/or respect for autonomy more important than we do, or promotion of autonomy and/or well-being and/or equality less important, taking a more longterm perspective is likely to shift the balance of reasons to favour a ban. Indeed, it seems to us merely a matter of how long a perspective one takes. If we consider all the people who will be born in this present century, it is hard to see how prevention of the more than one billion expected premature deaths and the substantial individual suffering that comes with it could be outweighed by respect for the choice of some present (and some future would-be) smokers and concern for the restrictions on freedom involved.

One concern we might have about making the case for a cigarette ban is that of a 'slippery slope': once we acknowledge the possibility that cigarettes should be banned, what would stop us from banning, say, certain types of food, alcohol or risky sports? In response, it is crucial to emphasise that arguments about banning or legalising any particular substances or activities need to be made on their own terms and focus on the characteristics of the activity or substance in question. Much of the argument we present here relies on a combination of features that is specific to cigarettes and could not be easily extended to other substances-such as the high risks for long-term users and the high level of addictiveness. At the same time, we think that the broad strategy we pursued here-going beyond questions about individual freedom to consider the well-being impact of smoking on different individuals-could be helpful in discussing the status of other substances and activities.

\section{CONCLUSION}

Philosophical arguments for bans typically focus on particular features of smoking choices-that they are irrational, nonvoluntary and/or unendorsed — that are taken to make it (fairly) unproblematic for policymakers to interfere. However, these arguments are too quick in two respects: first, many smoking choices do not, in fact, share the identified characteristic. Second, while irrationality, non-voluntariness and lack of endorsement may weaken our reasons for protecting choices, they certainly do not remove them entirely. Much of the opposition to bans rests precisely on the understanding that we have reason to respect people's choices, even when these choices are problematic in various respects. Our argument has sought to stake out a more nuanced position, which acknowledges and gives substantial weight to the potential of a ban to disrespect individual autonomy and restrict freedom but emphasises the well-being losses such a ban could avert.

Of course, the argument for a ban faces not only philosophical but also political opposition. However, the idea is slowly gaining

${ }^{\mathrm{x}}$ CIA World Factbook, https://www.cia.gov/library/publications/ the-world-factbook/geos/xx.html traction in the tobacco control community and various ways of phasing in such a ban are being explored. What is more, electronic cigarettes and the debate surrounding them could provide a helpful entry point towards a serious discussion about a ban on conventional cigarettes. E-cigarettes deliver nicotine to users in a way that is much more similar to conventional cigarettes than other currently available nicotine delivery systems. While the jury is still out on the harmfulness of e-cigarettes to users and bystanders, ${ }^{65}$ there is a decent chance that these devices will turn out to be much less harmful than conventional cigarettes. Appropriate regulation could help ensure that these harms remain below acceptable levels. To the extent that e-cigarettes can provide a substitute for conventional cigarettes, many of the costs associated with a ban-in terms of limiting freedom and forcing current smokers to quit-would be alleviated. At the same time, many of the concerns about e-cigarettes-for example, that they would act as a 'gateway' to conventional cigarettes ${ }^{66}$ and that they would 'renormalise' smoking ${ }^{67}$ - would fall away if conventional cigarettes are effectively banned.

Some readers may not agree with the weighing we have given to the different pros and cons of banning cigarettes. For these readers, a more cautious conclusion is that it is important to recognise the variety of considerations at stake, as well as the fact that the costs of a ban would diminish with respect to future generations as these would grow up without cigarettes. Our conclusion, however, is that in light of the substantial death and disease it could avert, the case for a complete and effective ban on the sale of cigarettes is very strong.

Acknowledgements The authors would like to thank Adina Preda for helpful comments on an earlier draft. KG's work is supported by the Swedish Research Council for Health, Working Life and Welfare (grant no. 2009-2189). KV's work is supported by the Fonds de recherche du Québec - Société et culture (grant no. 172569).

Competing interests None declared.

Provenance and peer review Commissioned; externally peer reviewed.

\section{REFERENCES}

1 Jha P. Avoidable deaths from smoking: a global perspective. Public Health Rev 2011;33:569-600.

2 Jha P, Peto R. Global effects of smoking, of quitting, and of taxing tobacco. N Engl J Med 2014;370:60-8

3 Proctor RN. Why ban the sale of cigarettes? The case for abolition. Tob Control 2013;22(Suppl 1):i27-30.

4 Daynard R. Doing the unthinkable (and saving millions of lives). Tob Control 2009;18:2.

5 Malone R, McDaniel P, Smith E. It is time to plan the tobacco endgame. BMJ 2014;348:g1453-3.

6 Proctor RN. Golden Holocaust. Univ of California Press, 2012

7 Walters EH, Barnsley K. Tobacco-free generation legislation. Med J Aust 2015:202:509-10.

8 Doll R, Peto R, Boreham J, et al. Mortality in relation to smoking: 50 years observations on male British doctors. BMJ 2004;328:1519.

9 Pirie K, Peto R, Reeves GK, et al. The 21st century hazards of smoking and benefits of stopping: a prospective study of one million women in the UK. The Lancet 2013;381:133-41.

10 ASH. Smoking statistics: illness and death. ash.org.uk. http://ash.org.uk/files/ documents/ASH_107.pdf (accessed 14 May 2015).

11 Schane RE, Ling PM, Glantz SA. Health effects of light and intermittent smoking: a review. Circulation 2010;121:1518-22.

12 Bjartveit $K$, Tverdal $A$. Health consequences of smoking 1-4 cigarettes per day. Tob Control 2005;14:315-20.

13 Stuber J, Galea S, Link B. Smoking and the emergence of a stigmatized social status. Soc Sci Med 2008:67:420-30.

14 Voigt K. Ethical concerns in tobacco control Nonsmoker and "nonnicotine" hiring policies: the implications of employment restrictions for tobacco control. Am J Public Health 2012;102:2013-8.

15 Lader D. Smoking-related behaviour and attitudes, 2007. Office for National Statistics, 2008. http://www.statistics.gov.uk/downloads/theme_health/ smoking2007.pdf (accessed 19 May 2009). 
16 Richardson K, Crosier A. Smoking and health inequalities. ash.org.uk. 2007.

17 Kunst A, Giskes K, Mackenbach J. Socio-economic inequalities in smoking in the European Union. Applying an equity lens to tobacco control policies. 2004. http:// www.ensp.org/files/socio.pdf (accessed 5 May 2009).

18 Hiscock R, Bauld L, Amos A, et al. Smoking and socioeconomic status in England: the rise of the never smoker and the disadvantaged smoker. J Public Health (Oxf) 2012;34:390-6.

19 Voigt K. Smoking and social justice. Public Health Ethics 2010:3:91-106.

20 Stead M, MacAskill S, MacKintosh A, et al. "It's as if you're locked in": qualitative explanations for area effects on smoking in disadvantaged communities. Health Place 2001;7:333-43.

21 Barbeau EM, Wolin K, Naumova E, et al. Tobacco advertising in communities: associations with race and class. Prev Med 2005:40:16-22.

22 Yerger VB, Przewoznik J, Malone RE. Racialized geography, corporate activity, and health disparities: tobacco industry targeting of inner cities. $J$ Health Care Poor Underserved 2007;18:10-38.

23 Apollonio DE, Malone RE. Marketing to the marginalised: tobacco industry targeting of the homeless and mentally ill. Tob Control 2005;14:409-15.

24 Kotz D, West R. Explaining the social gradient in smoking cessation: it's not in the trying, but in the succeeding. Tob Control 2009;18:43-6.

25 Hill S, Amos A, Clifford D, et al. Impact of tobacco control interventions on socioeconomic inequalities in smoking: review of the evidence. Tob Control 2014;23:e89-97.

26 Gostin LO. Tobacco endgame: the poverty conundrum. Hastings Cent Rep 2014;44:10-1

27 Schroeder SA, Morris CD. Confronting a Neglected Epidemic: Tobacco Cessation for Persons with Mental Illnesses and Substance Abuse Problems. Annu Rev Public Health 2010:31:297-314.

28 Berlin I. Two concepts of liberty. In: Liberty: Incorporating Four essays on liberty. Oxford: Oxford University Press, 2002, pp. 166-217.

29 Feinberg J. The interest in liberty on the scales. Values Morals 1978;13:21-35.

30 Carter I. A measure of freedom. Oxford: Oxford University Press, 2004.

31 Raz J. The morality of freedom. Clarendon Press, 1986.

32 Grill K. Respect for what? Choices, actual preferences, and true preferences. Soc Theory Pract 2015:41:692-715.

33 Goodin R. No smoking: the ethical issues. Chicago: University of Chicago Press, 1990

34 Dworkin G, Sugden SJB. Paternalism. Monist 1972;56:64-84.

35 Abdullah A, Husten C. Promotion of smoking cessation in developing countries: a framework for urgent public health interventions. Thorax 2004;59:623-30.

36 Chaloupka F, Jha P, Corrao M, et al. Global efforts for reducing the burden of smoking. Dis Manag Health Outcomes 2003;11:647-61.

37 Watson G. Skepticism about weakness of will. Philos Rev 1977:86:316-39.

38 Fernander $\mathrm{A}$, Rayens MK, Zhang $\mathrm{M}$, et al. Are age of smoking initiation and purchasing patterns associated with menthol smoking? Addiction 2010;105(Suppl 1):39-45.

39 Dunstan S. General lifestyle survey overview: a report on the 2010 general lifestyle survey. Office for National Statistics, 2012.

40 USDHHS. Preventing tobacco use among youth and young adults: a report of the surgeon general. Atlanta, GA: US Department of Health and Human Services, Centers for Disease Control and Prevention, National Center for Chronic Disease Prevention and Health Promotion, 2012.
41 Donny EC, Dierker LC. The absence of DSM-IV nicotine dependence in moderate-to-heavy daily smokers. Drug Alcohol Depend 2007;89:93-6.

42 Christman J. Autonomy in moral and political philosophy. In: Zalta E, ed. Stanford encyclopedia of philosophy spring edition. Stanford Encyclopedia of Philosophy (Spring 2015 edition), 2015.

43 Hanna J. Paternalism and the ill-informed agent. J Ethics 2012:16:421-39.

44 Kahneman D. Thinking, fast and slow. New York: Farrar, Straus and Giroux, 2011.

45 Conly S. Against autonomy: justifying coercive paternalism. New York: Cambridge University Press, 2013.

46 Thaler R, Sunstein C. Nudge: improving decisions about health, wealth, and happiness. New Haven \& London: Yale University Press, 2008.

47 Sunstein $\mathrm{CR}$, Thaler RH. Libertarian paternalism is not an Oxymoron. Univ Chicago Law Rev 2003;70:1159-202.

48 Elster J, Skog 0-J. Getting hooked. Cambridge: Cambridge University Press, 1999

49 Rachlin H. In what sense are addicts irrational? Drug Alcohol Depend 2007;90 (Suppl 1):S92-9.

50 Goodin R. The ethics of smoking. Ethics 1989:99:574-624

51 Benowitz NL. Nicotine addiction. N Engl J Med 2010;362:2295-303.

52 Fagerström K. Determinants of tobacco use and renaming the FTND to the Fagerstrom Test for Cigarette Dependence. Nicotine Tob Res 2012;14:75-8.

53 Bell K, Keane H. Nicotine control: e-cigarettes, smoking and addiction. Int J Drug Policy 2012;23:242-7.

54 Brennan P, Crispo A, Zaridze D, et al. High cumulative risk of lung cancer death among smokers and nonsmokers in Central and Eastern Europe. Am J Epidemiol 2006;164:1233-41.

55 Jha $\mathrm{P}$, Ramasundarahettige C, Landsman V, et al. 21st-century hazards of smoking and benefits of cessation in the United States. N Engl J Med 2013;368:341-50.

56 Goodin RE. Permissible paternalism: in defense of the Nanny State. Responsive Community 1991;1:42-51.

57 Fiore M. Treating Tobacco use and dependence: 2008 update. 2008. http://www. surgeongeneral.gov/tobacco/treating_tobacco_use08.pdf (accessed 9 Apr 2011).

58 Fong GT, Hammond D, Laux FL, et al. The near-universal experience of regret among smokers in four countries: findings from the International Tobacco Control Policy Evaluation Survey. Nicotine Tob Res 2004;6:S341-51.

59 Connolly GN, Behm I, Healton CG, et al. Public attitudes regarding banning of cigarettes and regulation of nicotine. Am J Public Health 2012;102:e1-2.

60 Shahab L, West R. Public support in England for a total ban on the sale of tobacco products. Tob Control 2010;19:143-7.

61 Wang MP, Wang $X$, Lam TH, et al. The tobacco endgame in Hong Kong: public support for a total ban on tobacco sales. Tob Control 2015;24:162-7.

62 Edwards R, Wilson N, Peace J, et al. Support for a tobacco endgame and increased regulation of the tobacco industry among New Zealand smokers: results from a National Survey. Tob Control 2013;22:e86-93.

63 Hayes L, Wakefield MA, Scollo MM. Public opinion about ending the sale of tobacco in Australia. Tob Control 2014;23:183-4.

64 Grill K. Liberalism, altruism and group consent. Public Health Ethics 2009;2:146-57

65 Grana R, Benowitz NL, Glantz SA. E-cigarettes: a scientific review. Circulation 2014; 129:1972-86

66 Bell K, Keane H. All gates lead to smoking: the "gateway theory," e-cigarettes and the remaking of nicotine. Soc Sci Med 2014;119:45-52.

67 Voigt K. Smoking norms and the regulation of e-cigarettes. Am J Public Health 2015:105:1967-72. 